\section{AS DIFICULDADES DE "PASSARO BASTÃO": PERSPECTIVAS DA SUCESSÃO DA PROPRIEDADE ENTRE PRODUTORES DE COMUNIDADES RURAIS DO MUNICÍPIO DE CAMPOS GERAIS/MG}

\author{
Denison Ferreira da Silva \\ Maria Lúcia Ribeiro ${ }^{2}$ \\ Henrique Carmona Duval \\ Vera Lucia S. Botta Ferrante 4
}

Resumo: Este trabalho tem como tema principal a hereditariedade e a sucessão da propriedade na agricultura familiar. Foi realizado um levantamento bibliográfico sobre o tema e foram aplicados questionários com dez famílias de duas comunidades rurais de Campos Gerais/MG. Entrevistas com agentes externos e as anotações em diário de campo durante as visitas às comunidades permitiram um conhecimento mais detalhado do objeto de estudo. Pôde-se verificar que não há explicitamente qualquer tipo de planejamento para a passagem da posse da propriedade, pois existe uma resistência das famílias em tratar da morte e discutir a continuidade da propriedade. No entanto, há evidências de que a sucessão, entendida enquanto um processo, se expressa em situações que indicam que estratégias para a sucessão são construídas historicamente.

Palavras-chave: Agricultura Familiar; Sucessão; Hereditariedade.
'Mestre em Desenvolvimento Territorial e Meio Ambiente, Universidade de Araraquara - Uniara. dfs.deninho@ gmail.com

Docente do PPG em Desenvolvimento Territorial e Meio Ambiente, Universidade de Araraquara - Uniara ${ }^{3}$ Docente do Centro de Ciências da Natureza, UFSCar Lagoa do Sino.

${ }^{4}$ Coordenadora do PPG em Desenvolvimento Territorial e Meio Ambiente, Universidade de Araraquara - Uniara.
Abstract: This work has as its main theme the heredity and succession of property in family agriculture. A bibliographic survey was carried out on the subject and questionnaires were applied with ten families from two rural communities of Campos Gerais / MG. Interviews with external agents and field diary annotations during the visits to the communities allowed a more detailed knowledge of the object of study. It could be verified that there is not explicitly any type of planning for the passage of ownership of the property, because there is a resistance of the families in dealing with the death and to discuss the continuity of the property. However, there is evidence that succession, understood as a process, is expressed in situations that indicate that strategies for succession are constructed historically.

Keywords: Family Agriculture; Succession; Heredity.

\section{Introdução: tendências para o declínio da população rural}

Um dos grandes desafios da reprodução social de famílias rurais é a questão sucessória, pois "passar o bastão" não é uma tarefa fácil na esfera familiar. Um dos fatores que problematizam a transmissão do comando de uma propriedade familiar são os desequilíbrios demográficos rurais, como os analisados por Costa (2013). Sua análise quanto às disparidades demográficas põe em risco a própria reprodução social das famílias, não apenas no Brasil, mas também em outros países. O estudo pormenorizado de Camarano e Abramovay (1998) organiza uma série de fatores que influem sobre a intensificação do êxodo rural brasileiro em meados do século XX. Esse processo assinalou a perda gradativa de características tradicionais, abrindo espaço para um possível desenraizamento por parte da população rural.

Os problemas enfrentados na agricultura pela falta de sucessores já se reproduzem em estudos comparados a partir de dados do Instituto Brasileiro de Geografia e Estatística (IBGE, 2010), nos censos entre os anos de 2000 e 2010, os quais indicam que a população rural diminuiu em 2 milhões de pessoas e, agora, representam $15,6 \%$ da população do Brasil.

O declínio da população rural aparece em tais dados em um período de tempo de doze anos 2001-2012; a população rural que era de 16,20\% diminuiu para $15,17 \%$. Observando este mesmo corte de tempo, a população urbana apresenta um crescimento de 83,88\% em 2001 para 84,83\% em 2012. 
Essa tendência no panorama demográfico nacional vem ocorrendo também no estado de Minas Gerais, com a progressão dos moradores urbanos de $83,4 \%$ para $84,5 \%$, à medida em que houve um recuo de $16,6 \%$ para $15,5 \%$ da população rural no mesmo período.

Parte desta queda pode ser atribuída ao processo de hereditariedade no campo. Observando a transmissão da propriedade rural desde sua posse, assim como o recebimento por herança, analisam-se vários casos em que há possibilidade de sua fragmentação. Como observa Carneiro (2001, p.22), em contexto de sucessão, tanto pode ocorrer a fragmentação da propriedade, como também pode favorecer a manutenção do patrimônio. Um dado significativo nessa discussão obtido no último censo agropecuário de 2006, aponta que o território brasileiro tem 5,2 milhões de estabelecimentos rurais e cerca de $29 \%$ foram obtidos por herança familiar (IBGE, 2006).

Esse resultado implica na necessidade de um debate sobre os sucessores nas famílias dos produtores rurais, já que os dados apresentados apontam para um possível esvaziamento rural, como indicado por Abramovay (1992) ao afirmar que o Brasil é marcado por um setor agroindustrial bem desenvolvido e tecnológico e, por outro lado, ainda lida em determinadas regiões com o coronelismo e com a falta de políticas públicas de estruturação que possam colocar o agricultor familiar em condições de produzir e comercializar seus produtos. Para Abramovay et al. (1998, p.56) "uma unidade produtiva sem sucessores dificilmente contará com os investimentos em capital, terra e formação necessários ao seu desenvolvimento".

Como o êxodo rural adquiriu característica seletiva, sobretudo entre jovens mulheres, Costa (2013) indica que a tendência geral no meio rural é marcada pela masculinização e pelo envelhecimento. Segundo Duval (2015), o matrimonio e a produção agropecuária são estratégias vitais para que os grupos rurais confirmem suas posições e regularidades de reprodução social. No entanto, o autor afirma que se continua a observar fenômeno identificado por Bourdieu (2004), de que as mulheres saem para as cidades em função de sua condição desprestigiada no processo sucessório no meio rural. Portanto, adotam estratégias como casamentos, formação escolar e trabalho fora de seus locais de origem, notadamente nas cidades, o que ocasiona o surgimento de fenômenos como o celibato masculino no meio rural.

Deve-se ressaltar também que as dificuldades de acesso à educação e à saúde têm causado a expulsão dos camponeses para as cidades, buscando trabalho e renda e desestimulando os jovens na continuidade da vida no campo, comprometendo a sucessão geracional. A grande maioria dos descendentes de famílias rurais se desloca para as cidades na busca de oportunidades de melhorarem de vida e atrás de uma renda assalariada. Conforme relata Alves (2006), as famílias rurais levam em consideração múltiplos aspectos ante a decisão de migrar:

Admite-se que a família tome decisões que visem ao bem-estar de todos os seus membros, embora o chefe de família possa sair perdendo. Viver no meio rural ou na cidade, são duas opções e os prós e os contras são devidamente avaliados. Na decisão de migrar para a cidade, o diferencial de salário, o desconforto do ajuste ao novo estilo de vida, o risco de não encontrar emprego e a violência urbana são devidamente considerados. Contudo, se o diferencial de salário for tentador e as vantagens que as cidades oferecem forem incorporadas a ele, a família corre o risco de migrar (ALVES, 2006 p.7).

Com base nestas tendências, o presente trabalho teve como objetivo construir um quadro de referências para se analisar o processo sucessório nas comunidades Capoeirinha e Dois Paus, no município de Campos Gerais/MG,

\section{Diferentes perspectivas e tendências sobre a sucessão}

Woortmann (1995) relata que o processo de transmissão do patrimônio familiar trata da transferência de bens de pais para filhos e, em especial, a terra através da herança constitui um dos movimentos básicos da agricultura familiar. Esse processo inicia-se na infância, conforme Burton e Walford (2005), pois a divisão sucessória é realizada em etapas. Nas famílias rurais, desde criança, a dedicação ao trabalho agrícola é dividida com o tempo dedicado aos estudos. São transmitidas funções de responsabilidades quanto a termos técnicos e passagem de conhecimentos produtivos. Se o pai sai da administração, passa-se a posse ao seu sucessor que adquire o saber-fazer do patriarca, geralmente o filho primogênito.

O tema da sucessão foi analisado por Gasson e Errington (1993), assinalando que o filho herdeiro pode morar em um determinado lugar separado do pai, gerindo de forma própria a tomada de decisão. Com sua vida financeira resolvida, o jovem assume o posto paterno após a aposentadoria dos pais, como também divide o mesmo teto que o pai e assume definitivamente o posto após o falecimento do mesmo. Por outro lado, Spanevello (2008) mostra que será possível delimitar um quadro sobre os prováveis acertos da transmissão do patrimônio familiar, ocorrendo casos 
de compra de terras para ajudar o filho sucessor. A transferência dessa terra ocorre tardiamente, para demonstrar que não perdeu sua autoridade perante o filho e, a partir do esgotamento da força física dos pais, os mesmos vão se retirando e cedendo o lugar para os filhos tomar conta do estabelecimento.

O processo de transmissão da herança, igualmente importante na perspectiva da família rural, compreende dois fatores que se complementam: 1) a escolha do sucessor, que geralmente mantém a unidade do grupo familiar; 2) a divisão dos bens (CARNEIRO, 2001). Os estabelecimentos não são um conjunto que possui igual natureza e/ou apresenta semelhança de estrutura e função, possuindo três tipos de unidades familiares: as essencialmente familiares, as que complementam sua força de trabalho com empregados temporários, e as que contratam empregados permanentes utilizando empregados temporários ou não conhecidos como empresas familiares (KAGEYAMA; BERGAMASCO, 1989). Estas situações, no entanto, podem variar em recortes de temporalidade, em função das dinâmicas de sucessão familiar.

Sabe-se da importância que a pequena propriedade exerce no funcionamento das dinâmicas produtivas no meio rural, envolvendo uma tradição familiar de enraizamento na terra. A preparação da passagem dos negócios aos herdeiros é de grande dificuldade e também pode ser frustrante, como afirma Longenecker et al. (1997). Os conflitos, na hora da sucessão, são os piores, pois sempre são expostos problemas estruturais de muitos anos. A sucessão é determinada por um longo prazo de acordo com a preparação que os pais deram aos filhos na relação de riqueza e poder (LODI, 1993).

A prática de negociação exercida dentro da família nem sempre obtém êxito, por mais habilidosa que seja feita, pois sempre existirão muitas emoções envolvidas podendo dissolver o mais robusto dos empreendimentos familiares (LESSA, 2003). Este autor aponta ainda a visão de competição entre os membros familiares, que exercem interferência na gestão da propriedade, criando conflitos de difícil solução na transmissão patrimonial.

Os pais, por sua vez, também podem se mostrar desconfiados com a capacidade dos filhos de gerenciar a propriedade tornando o contexto pouco favorável à continuidade. Essa prática de transferir a liderança de uma geração à outra é cercada de conflitos devido às diferenças de cultura entre gerações. A conciliação e o rompimento podem ser realizados conforme o modelo paternalista e os filhos possivelmente enfraquecem a cultura da família patriarcal, que sugere que o pai possui mais experiência do que o filho e, portanto, não cede muito espaço a este (LONGENECKER et al., 1997).

Atualmente, no Brasil, fecha-se ou divide-se em diversas empresas rurais familiares justificados pela incapacidade da estabilização de relações, já que a profissionalização da gestão é cada vez mais recente e a introdução de normas e regras auxilia bastante na sobrevida da empresa. A família tem que ser comprometida com a continuidade da propriedade, pois isso colocará o futuro em risco com apenas pequenos desentendimentos. Os herdeiros precisam de uma preparação em termos de adquirir um saberfazer, se inteirar sobre as formas de organização da produção, antecipando e planejando sua carreira como ponto de partida (LESSA, 2003). Portanto, os sucessores adquirem os modos de fazer tradicional dos pais e precisam, ao mesmo tempo, adquirir novas habilidades para participar de um mercado de agricultura moderna.

Conforme Abramovay (1998), a formação de novos jovens agricultores é um processo que envolve componentes como: a transferência de patrimônio; a continuação paterna na atividade profissional do campo; e a saída das gerações mais velhas da gestão patrimonial. Já as tendências gerais para as propriedades familiares são a especialização em uma atividade, diminuindo a utilização da mão de obra familiar ou partir para a venda ou arrendamento. Estes proprietários atingem uma idade elevada e poderiam se aposentar pelos mecanismos do Instituto Nacional do Seguro Social (INSS) e ganhar um salário que talvez sustente a família e se complemente com a renda da própria atividade econômica. Neste contexto, faz-se necessária uma análise mais aprofundada sobre a questão sucessória das pequenas propriedades agrícolas, atribuindo-se importância tanto às dinâmicas internas das famílias como ao contexto mais geral de reprodução social da agricultura familiar.

O presente estudo realiza a análise da sucessão familiar na região de Campos Gerais/MG enquanto um processo social. Em um contexto de difícil aposentadoria, divisão da propriedade, dilemas produtivos, êxodo rural, estratégias de trabalho e educação fora da propriedade, como os pais e filhos tratam da sucessão na esfera familiar? Que decisões e ações estão tomando? O trabalho pretende elaborar uma reflexão sobre alguns casos dessa transição, avaliando também as justificativas dos futuros herdeiros em continuar ou não na atividade rural.

\section{Procedimentos Metodológicos: o espaço da pesquisa}

Esta pesquisa foi desenvolvida em duas comunidades rurais do município de Campos Gerais/MG, Capoeirinha e Dois Paus, onde vivem aproximadamente 3.620 famílias. 
A escolha deste universo empírico de pesquisa é justificada pela população rural do município ser formada por cerca de 8.444 habitantes, ou seja, 30,6\% do total de habitantes que é de 27.600 habitantes (IBGE, 2010). O município apresenta uma área territorial de $769,504 \mathrm{Km}^{2}$, com cerca de $2.000 \mathrm{Km}$ de estradas vicinais e galhos de estradas com 5.000 propriedades segundo a Secretaria de Agricultura da Municipalidade.

O critério de seleção destas localidades foi baseado por estas comunidades serem formadas exclusivamente por agricultores familiares e possuírem uma ampla diversidade produtiva e por empregar mão-de-obra familiar. Além disso, as duas comunidades são as mais populosas do município, segundo a Paróquia Nossa Senhora do Carmo, de Campos Gerais, Diocese de Campanha, possuem, ao todo, 250 famílias. Os núcleos familiares escolhidos para essa pesquisa foram pequenos proprietários.

\section{Dificuldades da pesquisa de campo e algumas similaridades entre as famílias}

Para o delineamento do estudo enfrentamos uma série de percalços dos quais destacamos a dificuldade de se aproximar dos sujeitos da pesquisa. Quanto à escassez de levantamento de dados referentes à cidade de Campos Gerais, encontramos apenas aqueles do IBGE, da Empresa de Assistência Técnica e Extensão Rural de Minas Gerais (EMATER/MG) e fontes extraoficiais da Prefeitura Municipal, aliados à desconfiança de moradores da zona rural em fornecer informações locais e a várias tentativas negadas de conseguir autorização, junto à Diocese de Campanha, para se ter acesso ao livro Tombo, que descreve as rotinas do município antes da implantação oficial dos cartórios.

No entanto, foi justamente por meio da Diocese que se pôde selecionar os sujeitos da pesquisa. O caminho a ser percorrido foi iniciado por meio da forte influência, principalmente nas zonas rurais, da Igreja Católica Apostólica Romana,-através de inúmeras e longas conversas com habitantes do município, o que nos encaminhou ao pároco da cidade de Campos Gerais. Este, após entender os objetivos e a importância da nossa proposta, forneceu em um primeiro momento o número de famílias de cada comunidade rural do município. Dentre estes dados destacaram-se as duas comunidades selecionadas por apresentarem o maior número de famílias em relação às demais. A solicitação de contatos com os líderes das comunidades das duas localidades foi também facilitada pelo bom relacionamento entre o representante da Igreja e os das comunidades. Foi possível verificar, admitido pelo pároco, que há conflitos referentes às comunidades rurais e, geralmente, os líderes locais são escolhidos de acordo com a sintonia com a Igreja. O comprometimento com os trabalhos comunitários e as responsabilidades para estimular a religiosidade da localidade são fortemente considerados. Evidencia-se que em relação à escolha de lideranças locais, a Igreja opta por escolha pontual para, essencialmente, manter sua grande influência estimulada pela religiosidade e evitar rompimento de relacionamento entre moradores e Igreja.

A indicação pelos líderes das comunidades das famílias que participariam do estudo apontou, novamente, uma tendência para aquelas alinhadas com os princípios da religião católica e em sintonia com o líder da comunidade. A partir dessas premissas foram selecionadas dez propriedades das duas localidades, tendo em vista os aspectos e características relevantes para a pesquisa como similaridades e diferenças, condições geográficas de relevo em áreas planas ou com declive, facilitando ou dificultando a atividade agrícola, influenciando a renda e causando diferenças econômicas com os atores da pesquisa.

Todas as famílias participantes da pesquisa têm semelhanças, como: a participação nas reuniões das associações rurais; a realização de trabalho coletivo organizado por meio de mutirões; exploração diversificada da propriedade com a produção de café, torrefação, apicultura, o cultivo de plantas e criação de animais para autoconsumo. Apesar de serem aspectos do modo de vida que se assemelham dentre as famílias das comunidades, existem diferenças, sobretudo com relação à posse das terras, herança e problemas com sucessão, que serão observadas na discussão dos resultados da pesquisa.

Outra observação importante quanto à chegada às comunidades é que as famílias demonstraram grande satisfação em participar da pesquisa, mostrar todas as rotinas da propriedade rural, exibindo o trabalho de anos na propriedade como se fosse um troféu por conseguirem sobreviver a todas as dificuldades que a vida lhes impôs - o que certamente torna a passagem de comando da propriedade para os filhos ainda mais cuidadosa.

Técnicas de pesquisa para a coleta de informações

A abordagem da questão sucessória foi desenvolvida através da aplicação 
de questionários às dez famílias, sendo cinco em cada comunidade, guiados por um roteiro com perguntas qualitativas. $\mathrm{O}$ questionário foi dividido em três blocos abordando os seguintes aspectos: características do núcleo familiar da propriedade; continuidade das atividades agrícolas e transmissão patrimonial. A validação do questionário foi realizada pela aplicação do mesmo a três proprietários rurais não participantes da pesquisa para fins de ajuste.

A coleta de dados nas comunidades Capoeirinha e Dois Paus foi realizada em cerca de quatro semanas, durante o mês de abril de 2016. Cabe ressaltar que a aplicação dos questionários se deu em período muito próximo à colheita do café, na qual é primordial toda a preparação para a colheita.

Os questionários foram aplicados, em sua maioria, com o casal e embora as respostas tenham sido dadas pelo homem, considerado "chefe de família", a esposa sempre que achava necessário intervia em alguma resposta do marido. Convém observar que o marido sempre achava necessário consultar a esposa, principalmente em questões familiares. Mas, além disso, as esposas mostraram conhecer toda a rotina da propriedade rural. Em muitas famílias as esposas não paravam com os afazeres domésticos, ao mesmo tempo que davam toda atenção à pesquisa e intervinham na resposta quando achavam necessário. As respostas dos questionários aplicados foram gravadas com a autorização e consentimento de ambos.

Todas as observações quanto à participação das mulheres nas conversas, bem como outras que surgiram no momento da pesquisa de campo, foram registradas no diário de campo. Este também serviu para se completar as informações sobre os sistemas produtivos nos momentos de caminhadas transversais pelas propriedades, nos quais também foram realizados registros fotográficos. Para complementar as informações foram entrevistados agentes externos como o técnico da EMATER, um representante da Secretaria Municipal de Agricultura e o pároco.

\section{Discussão e resultados: apresentando o perfil e as diferenças entre as famílias}

Para iniciar esta seção, apresentamos no Quadro 1, a seguir, algumas semelhanças e diferenças das famílias quanto às principais questões que norteiam a presente investigação.

A análise destes dados aponta que a trajetória de trabalho das famílias investigadas é majoritariamente rural e suas propriedades foram adquiridas
Quadro1- Similaridades e diferenças das famílias das comunidades Capoeirinha e Dois Paus.

\begin{tabular}{|c|c|c|c|c|c|}
\hline Família & Origem & $\begin{array}{l}\text { Trajetória } \\
\text { ocupacio- } \\
\text { nal }\end{array}$ & $\begin{array}{l}\text { Forma de } \\
\text { aquisição } \\
\text { da terra }\end{array}$ & $\begin{array}{l}\text { Número } \\
\text { de pessoas } \\
\text { residentes }\end{array}$ & $\begin{array}{l}\text { Número } \\
\text { de filhos } \\
\text { homens/mu- } \\
\text { lheres }\end{array}$ \\
\hline 1 & Capoeirinha & $\begin{array}{l}\text { Trabalha- } \\
\text { dor rural }\end{array}$ & $\begin{array}{l}\text { Parte por } \\
\text { herança } \\
\text { Parte por } \\
\text { aquisição }\end{array}$ & 4 pessoas & $1 / 1$ \\
\hline 2 & Capoeirinha & $\begin{array}{l}\text { Trabalha- } \\
\text { dor rural }\end{array}$ & $\begin{array}{l}\text { Parte por } \\
\text { herança } \\
\text { Parte por } \\
\text { aquisição }\end{array}$ & 5 pessoas & $1 / 2$ \\
\hline 3 & Capoeirinha & $\begin{array}{l}\text { Trabalha- } \\
\text { dor urbano }\end{array}$ & Posse & 4 pessoas & $2 / 0$ \\
\hline 4 & Capoeirinha & $\begin{array}{l}\text { Trabalha- } \\
\text { dor rural }\end{array}$ & Posse & 6 pessoas & $2 / 2$ \\
\hline 5 & Capoeirinha & $\begin{array}{l}\text { Trabalha- } \\
\text { dor rural }\end{array}$ & Herança & 4 pessoas & $2 / 0$ \\
\hline 1 & Dois Paus & $\begin{array}{l}\text { Trabalha- } \\
\text { dor rural }\end{array}$ & Posse & 4 pessoas & $1 / 1$ \\
\hline 2 & Dois Paus & $\begin{array}{l}\text { Trabalha- } \\
\text { dor rural }\end{array}$ & Posse & 4 pessoas & $1 / 1$ \\
\hline 3 & Dois Paus & $\begin{array}{l}\text { Trabalha- } \\
\text { dor rural }\end{array}$ & Posse & 6 pessoas & $2 / 2$ \\
\hline 4 & Dois Paus & $\begin{array}{l}\text { Trabalha- } \\
\text { dor rural }\end{array}$ & Posse & 6 pessoas & $0 / 4$ \\
\hline 5 & Dois Paus & $\begin{array}{l}\text { Trabalha- } \\
\text { dor rural }\end{array}$ & $\begin{array}{l}\text { Parte por } \\
\text { herança } \\
\text { Parte por } \\
\text { aquisição }\end{array}$ & 4 pessoas & $0 / 2$ \\
\hline
\end{tabular}

Fonte: Pesquisa de Campo, 2016.

por meio da posse. Em três casos, as aquisições das terras foram em parte por meio de herança e em parte por meio de compra e, em apenas um caso, a propriedade toda foi herdada. Embora existam essas características comuns à maioria das famílias, existem especificidades em termos da ocupação dos 
pais, filhos e filhas e quanto aos sistemas produtivos nas propriedades, sendo que esses foram aspectos compreendidos como fundamentais para se analisar as perspectivas de sucessão familiar e serão abordados no presente artigo.

Cabe destacar, dentre as famílias investigadas, algumas situações específicas quanto às possibilidades de sucessão. Cada um dos exemplos a seguir, mostra uma posição possível para as perspectivas de permanência dos filhos na propriedade ou mesmo para permanecer perto da família, bem como indica a chance de filhos que não possuem interesse na propriedade familiar e na continuidade na atividade agropecuária.

Com relação a essas diferenças entre as famílias, em duas delas, os homens são irmãos, e os herdeiros mais velhos já trabalham efetivamente no sistema produtivo, principalmente no café. Em ambas houve estímulo para se trabalhar com os pais e, desde cedo, os filhos descobriram a vocação para o manejo com a terra. Outra família também se destacou na lavoura de café, conseguindo implementar o seu sistema produtivo e até investir em uma torrefação de café. A partir desses três casos ficou claro que as famílias que possuem sistemas produtivos, baseados no café, possuem melhor estruturação e continuidade, já que é uma região típica de cafeicultores de várias gerações. $\mathrm{O}$ fato destas três famílias se destacarem na produção cafeeira e no envolvimento dos filhos no trabalho nas propriedades levanta a hipótese de que são famílias com maior potencial para a continuidade na terra e sucessão.

Em outra família, o casal nasceu na zona rural e a vida inteira trabalhou para outros proprietários. Fez suas economias, comprou sua gleba de terra e hoje cria seus filhos demonstrando os valores e as dificuldades para se chegar a ser proprietária. Atualmente, a família se sustenta da apicultura e produção de leite, utiliza a amizade com outros proprietários para a instalação das caixas de abelhas perto de áreas de proteção ambiental de outras propriedades. Neste caso, sistemas produtivos com foco em outros produtos, que não o café, podem significar uma maior fragilidade quanto à permanência na terra e até certa dependência do apoio comunitário.

A dimensão produtiva foi considerada de extrema relevância para as possibilidades de sucessão e permanência na terra. Sendo assim, segundo a entrevista com os representantes da EMATER/MG, há um importante trabalho realizado junto aos produtores quanto à assistência técnica, que interfere na possibilidade de se praticar uma agricultura mais diversificada e assim aumentar os rendimentos das famílias, favorecendo a permanência na atividade. Observamos que se realizam programas que têm esse propósito, como o Minas sem Fome, no qual são distribuídas sementes das mais variáveis hortaliças e cereais, promovendo a diversificação agrícola e a segurança alimentar. A feira do produtor também oferece boa oportunidade para o escoamento da produção diversificada. Por outro lado, a associação rural e as reuniões comunitárias fortalecem bastante as relações entre os pequenos agricultores e as formas de organização e comercialização da produção.

É importante frisar o caso de outra família que largou toda uma vida em uma grande cidade (São Paulo), buscando qualidade de vida no campo. Deixaram a vida na capital, compraram um lote de terras, investiram em piscicultura. Após o estabelecimento em definitivo, a mulher conseguiu passar em concurso público e hoje possui um salário que compõe o sustento familiar com a sua renda externa.

Cabe salientar que em uma propriedade corre-se sérios riscos de não haver sucessão devido ao desinteresse dos herdeiros. Segundo os pais, tentou-se diversas táticas para despertar o interesse, e os filhos já adolescentes não corresponderam. O casal estimulou os filhos a tomarem conta de alguns pés de café em troca de receberem tudo o que os pés de café produziam, só que não obteve o êxito desejado. Isso fez com que o proprietário arrendasse parte das terras, já que é aposentado por invalidez e a esposa é funcionária pública, havendo uma renda externa para o sustento. A incerteza de futuro na terra para os filhos se dá por não apresentarem a identidade com a propriedade rural e isso faz com que o risco do seu desaparecimento seja cada vez maior.

Com este breve quadro sobre o perfil de algumas famílias se pretendeu demonstrar que existem diferenças substanciais entre elas não apenas quanto às possibilidades de sucessão, mas também quanto ao histórico de permanência da família naquele território, quanto aos sistemas produtivos, quanto ao interesse dos sucessores em se apropriar ou não do comando da propriedade. São diferenças que apontam para a complexa relação da hereditariedade em cada uma das famílias, acompanhadas por aspectos que lhes fogem ao controle como o mercado de produtos agropecuários e as dinâmicas territoriais, não abordadas no âmbito deste artigo.

No entanto, é possível apontar que dentre as famílias da amostragem, aquelas que produzem café possuem uma situação mais favorável em função da tradição desse sistema produtivo na região e da melhor estruturação da propriedade. Mesmo assim, das quatro famílias que lidam com café, em uma delas, os herdeiros demonstraram desinteresse em permanecer na atividade, 
o que nos leva sempre a priorizar na análise da sucessão o viés da diferença e das especificidades de cada família.

\section{Sucessão nas comunidades rurais: uma questão invisível?}

Observamos que o tema da sucessão rural passou longe das porteiras das comunidades estudadas. $\mathrm{O}$ assunto nem sempre é tratado com seriedade necessária entre as lideranças rurais, associações de produtores e Secretaria de Agricultura, talvez por se tratar de um aspecto muito particular na esfera das decisões das famílias e carecer de um refinamento metodológico para mensuração. Alguns órgãos oficiais como EMATER tentam realizar estudos sobre essas consequências, que a médio e longo prazo poderão trazer desafios para a produção de alimentos na agricultura familiar (MINAS GERAIS, 2004; EMATER, 2016).

$\mathrm{O}$ assunto precisa ser introduzido de forma mais abrangente e concisa, buscando alternativas contra as incertezas que circundam a sucessão familiar. Diferentemente dos setores secundários e terciários, nos quais há uma preocupação na passagem de bastão entre uma geração e outra para o comando dos negócios familiares, esta situação é quase sempre inexistente no setor rural.

O proprietário rural também não é o único responsável por essa situação, já que o mesmo nunca recebeu qualquer tipo de instrução, incentivo e capacitação sobre o tema, deixando-o com "os pés e mãos amarradas" para se tratar do assunto. É de fundamental importância capacitar o pequeno produtor de maneira adequada dentro da sua linguagem, estimulando uma proposição diária sobre sucessão e assim ser discutida com a família. Caso contrário, será sempre uma discussão fundamentada na intuição e na emoção dos proprietários.

Resgatar o assunto sobre a sucessão demonstra que somente há preocupação depois da morte do produtor. A resistência apresentada dos produtores com a questão da morte demonstra ser quase um "azar" o tratamento do assunto de forma natural. Os sucessores não gostam de se expressar e visivelmente não houve qualquer preocupação ou preparação para quando este evento natural acontecer. $\mathrm{O}$ tema mexe bastante com as emoções da família, porém este assunto tem que ser tratado de uma forma o mais profissional possível, como uma forma de planejamento da continuidade da família e da propriedade.
Para os que defendem a continuidade, o ideal é que os filhos estejam engajados no trabalho na propriedade e na produção de alimentos que a agricultura familiar oferece. O processo sucessório precisa ser administrado com cautela, preparação adequada e introduzido no dia a dia das famílias, para que a transferência ocorra sem qualquer sequela ao meio produtivo e ao desmembramento da propriedade.

Notamos até um discurso alinhado entre todas as famílias desta comunidade com relação à recomendação aos sucessores de não realização da venda da propriedade, incentivando a ficar na terra. Os pais definitivamente não querem a venda da propriedade.

Porém, o jovem precisa estar a par que tem uma propriedade nas mãos, precisa, como ninguém, colocá-la para funcionar. Os cursos de capacitação, novos conhecimentos e métodos produtivos são fundamentais para a manutenção da propriedade. Buscar a sensibilidade dos pequenos produtores rurais sobre a sucessão é o maior desafio até então encontrado.

Tais aspectos podem ser facilmente observados em algumas falas dos atores desta pesquisa: 1) "Espero que continuem na atividade, mas nunca se sabe". 2) "Vou continuar aqui até ter saúde! Não pretendo voltar para a cidade de jeito nenhum"! 3) "Pretendo ficar aqui até o fim, até morrer! Não quero voltar para São Paulo mais não, embora financeiramente muitas vezes tenho vontade. Você viaja para lá e fica doidinho para voltar [para o meio rural]"! Estes depoimentos demonstram a dúvida colocada quanto às decisões para a sucessão, sendo notada nas falas a falta de planejamento.

Nos próximos depoimentos, podemos notar que mesmo que não haja planejamento quanto à sucessão, uma estratégia utilizada para a continuidade da propriedade é segurar os filhos até o leito de morte. Este é mais um exemplo de que a sucessão é diretamente ligada à morte do proprietário: 1) "Os filhos querem permanecer comigo até a velhice". 2) "Muito difícil! Os meninos não gostam de roça! Eu já estou perrengue”!

Um dos nossos questionamentos foi em relação à alguma propriedade em que a sucessão já tenha acontecido, para se investigar como se deu a sucessão de fato. Na comunidade da Capoeirinha pode-se relatar um caso de uma família que se encontra no processo sucessório. Somente o filho mais velho participou da entrevista, uma vez que sua irmã manifestou estar de acordo com a opinião do irmão e confirmando uma tendência à transmissão do comando ao primogênito masculino.

Indagado sobre o processo de transição, o mesmo salientou que não ocorreu 
ainda, porém a responsabilidade de tomar conta da propriedade já se encontra em suas mãos. Relatou ainda que os laços familiares se fortalecem com uma boa convivência desde a infância entre todos os membros familiares. $\mathrm{O}$ sucessor sempre foi estimulado pelos pais a aprender todas as rotinas do campo e, através daquele aprendizado, foi condicionado a ter gosto pela atividade desenvolvida, enquanto a irmã foi estimulada a se dedicar aos estudos até sua formação profissional como farmacêutica - profissão que exerce fora da propriedade. Segundo o relato, os atritos familiares são resolvidos com um planejamento onde há consenso de todos os membros familiares, cada um expondo a sua opinião a um virtual ou real problema a ser transposto.

$\mathrm{O}$ trabalho na propriedade tem assiduidade somente do pai, mãe e filho (sucessor), sendo que a filha ocasionalmente ajuda. Os pais ainda têm a palavra final, porém a mão de obra mais pesada é responsabilidade do filho com contribuições do pai, visando o aprendizado e manutenção da propriedade. Os resultados com a produtividades da propriedade são cobrados diretamente ao sucessor e apresentados de forma transparente para o aval financeiro do pai que confecciona os cheques para quitar as dívidas; os questionamentos necessários e as cobranças pela excelência administrativa da propriedade são inevitáveis. Somente em extrema necessidade de mão de obra que a irmã participa do trabalho como o plantio de feijão, colheita do café dentre outras atividades, uma vez que ela trabalha fora.

O sucessor não tem planos de abandonar a propriedade, pois adora as rotinas do campo e já sabe que essa atividade garante a sua sobrevivência. A irmã possui outros planos, mas por enquanto não abre mão de morar na propriedade, trabalhar na cidade e auxiliar, dentro das possibilidades, na manutenção da propriedade e cuidado dos pais idosos.

Pelo menos até o momento, e a partir do que foi relatado, a relação entre o irmão e a irmã tem se mantido fraterna e cordial em qualquer eventualidade. Para o sucessor não há nenhuma facilidade quanto à sucessão. Sempre há troca da mão de obra do pai para com o filho e a aprendizagem ocorre de forma gradativa e natural. Importante enfatizar que a morte é sempre um assunto delicado e difícil para estabelecer um diálogo. Apesar de ser uma realidade próxima e natural, quando a pauta do assunto é colocada logo é contornada, sendo tocada de forma rápida e ligeira, dando uma sensação de que se falar da morte é algo que não traz sorte, crença que parece influenciar as representações dos agricultores sobre a sucessão.

É muito difícil fazer uma projeção futura sobre a destinação da propriedade na falta dos pais, mas o bom relacionamento entre os sucessores que vem desde o berço faz com que os pais acreditem que a propriedade não vai se dividir.

\section{A ocupação dos filhos e filhas como um desenho da sucessão}

A ocupação dos sucessores mostra que a grande maioria de ambos os gêneros, nas famílias participantes do estudo na comunidade Capoeirinha, ainda se situa como dependente dos pais, pois foi observado que seis sucessores e quatro sucessoras são dependentes - o que pode se observar pela média de idade dos sucessores. Por outro lado, um sucessor é produtor rural e outro é operador de máquina de bordar, enquanto que uma sucessora é farmacêutica, conforme se segue:

- Sucessores masculinos: produtor rural (1), operador de máquinas (1), dependentes dos pais (6), sendo que dois deles têm entre 1 e 9 anos, três entre 10 e 19 anos e três com idade entre 20 e 29 anos.

- Sucessoras femininas: farmacêutica (1), dependentes dos pais (4), sendo que quatro delas possuem entre 10 e 19 e uma entre 20 e 29 anos.

Em relação à ocupação dos sucessores nas famílias participantes do estudo da comunidade Dois Paus, apenas uma sucessora é dependente, o restante, tanto masculino como feminino, possuem ocupação diversificada, como pode ser observado a seguir:

- Sucessores masculinos: produtor rural (3) e comerciante (1), sendo três deles acima dos 30 anos e um entre 10 e 19 anos.

- Sucessores femininos: comerciante (3), autônomo (1), administrador de empresa (1), manicure (1), professor (1), empregada doméstica (1), do lar (1), sendo uma delas com idade entre 10 e 19 anos, cinco entre 20 e 29 anos e quatro delas acima de 30 anos.

O fato de os interlocutores da pesquisa não mencionarem nenhuma vez que há produtoras rurais entre os sucessores demonstra um desenho de sucessão, que aponta tendência ao gênero masculino como sucessor na propriedade rural, só que isso nunca é declarado de maneira espontânea pelos 
casais, possivelmente para se evitar algum conflito entre os herdeiros. Nem a sucessora classificada como "do lar" foi considerada enquanto produtora rural.

Neste sentido, é interessante notar também que, no caso da família já mencionada, a sucessora feminina que possui curso superior em Farmácia, ainda mora com os pais e conhece e colabora com toda a rotina da propriedade, tem uma ligação muito estreita com os pais. Quando foram iniciadas as perguntas sobre sucessão, inevitavelmente a conversa acabou girando em torno do processo perecível da vida, causando grande desconforto da filha e muitas brincadeiras, quando se tratou da morte pelo casal, como, por exemplo: "Filha o que vai fazer quando eu e sua mãe batermos as botas?" A filha até se retirou momentaneamente da sala onde a pesquisa era realizada e deu a perceber seu tom bem sério, dirigido aos pais: "Vocês podem parar com essa brincadeira! Não gosto nem de pensar quando isso acontecer!".

\section{Considerações finais}

O trabalho visou conhecer se há preocupação com a continuidade sucessória no campo considerando que os últimos levantamentos do Censo apontam diminuição significativa da população rural deslocando-se para as cidades.

No que tange à pesquisa, procurou-se aplicar questionário a 10 proprietários das comunidades rurais da Capoeirinha e de Dois Paus, no município de Campos Gerais/MG, priorizando, na medida do possível, que o questionário fosse respondido pelo casal.

Verificamos que ambas as comunidades rurais não apresentam nenhum tipo de planejamento sucessório, mas existe um reconhecimento sobre a importância do assunto. Quando o assunto vai para o planejamento sucessório é inevitável que a conversa entre no campo da morte, gerando grande desconforto com o assunto.

Porém, são muitos os fatores que se relacionam na sucessão e na continuidade familiar na terra. Para Cândido (1979 p.17):

(...) conhecer os meios de vida num agrupamento de caipiras: quais são, como se obtém, de que maneira se ligam à vida social, como se refletem as formas de organização e as de ajustes ao meio [...] aquelas recorrem à descrição, atém-se aos detalhes e às pessoas, a fim de integrá-los numa visão que abranja, em princípio, todos os aspectos da cultura.

Em função disso, embora as discussões sobre o planejamento familiar para a sucessão não ocorram, enquanto eventos determinados, podemos auferir que, na prática, as situações são historicamente desenhadas e foram observadas nesta pesquisa por meio da ocupação dos possíveis sucessores.

As suposições no planejamento sucessório são perigosas, pois existem constantes interferências em diferentes momentos, nos quais a garantia e a manutenção da propriedade remetem a uma incógnita, que poderá ser alterada com o passar dos anos. Um exemplo disso são as estratégias matrimoniais das famílias a partir da existência de filhos e/ou filhas, possivelmente sucessores. Este trabalho demonstrou que a permanência dos filhos homens na propriedade é uma tendência no caso da Comunidade da Capoeirinha, diferente do que ocorre com a Comunidade de Dois Paus, que apresenta um número maior de mulheres como sucessoras e a permanência na propriedade possivelmente depende de seu cônjuge, já que suas ocupações não são vinculadas à produção rural.

É preciso acentuar que nas duas comunidades houve muitas mudanças, no dia a dia, devido à grande expansão econômica e introdução de novas racionalidades da agricultura moderna, mas também da permanência de muitas formas de convívio em comunidade, tais como trabalho em mutirão e as missas comunitárias. Todas as famílias investigadas contaram que "as condições de vida hoje são bem mais fáceis do que as de antigamente". Em uma família, o marido chegou a falar que "o maquinário disponível hoje em dia deixa bem mais fácil o trabalho do que antigamente, quando tinham que pegar no cabo da lacraia" referindo-se à enxada.

Em relação aos planos sucessórios para a continuidade na atividade constatou-se, por unanimidade, a preocupação dos agricultores para a continuidade da atividade pelos filhos. Entretanto, este assunto é tratado como tabu pelos membros das famílias dado o grande receio em discutir este tema que envolve tanto a morte individual de um ente querido como também coloca em questão a própria reprodução social e cultural do grupo familiar.

Por meio do exame da ocupação dos possíveis sucessores, há uma tendência à sucessão das propriedades e à passagem de sua gestão para os filhos homens, enquanto as mulheres possuem outras ocupações fora da propriedade. Porém, cabe ressaltar as famílias com filhos e filhas, cujos casais não manifestaram preferência por um dos gêneros para a continuidade na propriedade. Simplesmente o único pedido que fizeram aos filhos é que não vendessem de forma nenhuma a propriedade devido ao grande valor emocional. 
Em um núcleo familiar composto por dois filhos aconteceu uma curiosidade: nenhum dos dois filhos apresentou interesse na continuidade na propriedade. Diante dessa situação, o pai teve que responder ao questionário sussurrando, pois “os filhos não podem ficar sabendo, não gostam que eu fale com os outros sobre isso". Em outra família, até o momento, os sucessores mostraram-se desinteressados, fato que obrigou o pai a arrendar a maioria das terras, mesmo alertando os filhos que aquele pedaço de chão tem um valor inestimável para ele. Ao que tudo indica, a sucessão irá ocorrer, mas a distribuição das terras em forma de testamento é praticamente um assunto que não se fala em vida.

Diante dessas considerações, mesmo que a composição de idade e nível educacional dos sucessores sejam bastante diversificados, alguns já até assumiram o controle de algumas atividades produtivas e até então não houve disputas entre os sucessores e nem mesmo a preferência de algum dos filhos para continuarem na atividade. A única preocupação evidente dos pais é com relação ao possível casamento dos sucessores já que, segundo eles, podem ser intensamente influenciados pelos seus cônjuges.

A sucessão pode ocorrer pelo convívio geracional, onde os valores passados pelos pais durante a "criação" determinam a vontade que cada sucessor apresenta para a manutenção da pequena propriedade. Embora aconteça enquanto um processo, há que se examinar as estratégias matrimoniais e produtivas das famílias, além da ocupação dos filhos e filhas. Resta conhecer o que ocorrerá depois do casamento dos sucessores, como os cônjuges irão agir a respeito da herança após a morte dos pais. Será que todos esses valores passados durante a criação serão levados em conta? Será que as condições para a produção agropecuária se manterão favoráveis ao incremento da renda familiar, assim como as outras fontes de renda? Tais indagações podem ser válidas para a continuidade de pesquisas que possam investigar a sucessão familiar enquanto um processo e se há um planejamento prévio para a sucessão por parte de outras famílias das pequenas propriedades rurais.

\section{Referências}

ABRAMOVAY, R. et al. Juventude e agricultura familiar: desafios dos novos padrões sucessórios. Brasília: Unesco, 1998.
ABRAMOVAY, R. Paradigmas do capitalismo agrário em questão. Estudos Rurais. São Paulo/ Campinas: Editoria Hucitec/Anpocs, 1992.

ALVES, E. Migração Rural-urbana, agricultura familiar e novas tecnologias. In: Embrapa informação tecnológica. Brasília, DF, 2006, p.7-176.

BOURDIEU, P. El Baile de los Solteros. La crisis de la sociedad campesina em el Bearne. Barcelona: Editorial Anagrama, 2004.

BURTON, R.; WALFORD, N. Multiple sucession and land division on family in the South East of England: A counterbalance to agricultural concentration? Journal of Rural Studies, Londres, v.21, p.335-347, 2005.

CAMARANO, A. A.; ABRAMOVAY, R. Êxodo rural, envelhecimento e masculinização no Brasil: panorama dos últimos cinquenta anos. Revista Brasileira de Estudos de População, v. 15, n. 2, p. 45-66, jul./dez. 1998.

CÂNDIDO, A. Os Parceiros do Rio Bonito. Estudo sobre o caipira paulista

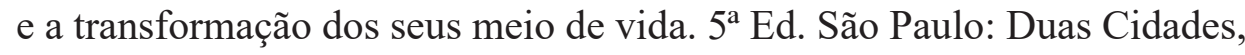
1979.

CARNEIRO, M.J. Herança e gênero entre agricultores familiares. Revista Estudos Feministas [online], vol.9, n.1, pp. 22-55, 2001.

COSTA, C. da. Contornos do celibato no espaço rural: solteirões do sul do Brasil. Extensão Rural, Santa Maria, v.20, n.3, p.22-51, set./dez., 2013.

DUVAL, H. C. Bens Materiais e Simbólicos: condição camponesa e estratégias familiares em assentamentos rurais na região central do Estado de São Paulo. Tese (Doutorado em Ciências Sociais). Universidade Estadual de Campinas, Instituto de Filosofia e Ciências Humanas - IFCH. Campinas 2015.

GASSON, R.; ERRINGTON, A. The farm family business - Wallingford, Cab International, 1993, $290 \mathrm{p}$.

IBGE - Instituto Brasileiro de Geografia e Estatística. Disponível 
em: <http://censo2010.ibge.gov.br/sinopse/webservice/frm_urb_rur. php? codigo $=311160>$. Acesso em: 30 ago. 2015.

IBGE - Instituto Brasileiro de Geografia e Estatística. Disponível em: $<$ http://downloads.ibge.gov.br/downloads_estatisticas.htm>. Acesso em: 30 ago. 2015.

IBGE - Instituto Brasileiro de Geografia e Estatística. Disponível em: $<$ http://www.ibge.gov.br/home/estatistica/pesquisas/pesquisa_resultados. php?id_pesquisa $=40>$. Acesso em: 26 set. 2015.

IMA- Instituto Mineiro de Agropecuária. Disponível em: $<$ http://www.ima. mg.gov.br/certificacao/cafe $>$. Acesso em: 03 out. 2015.

KAGEYAMA, A.; BERGAMASCO, S. M. P. Novos dados sobre a produção familiar no campo. XXVII Congresso da SOBER, 1989, Piracicaba/SP. In: Anais..., 1989.

LESSA,C. M. Riscos na sucessão em empresas familiares. Disponível em: <http:// www.jps.com.br/artigos/familiar_port.pdf.>. Acesso em:02 nov. 2015

LODI, J.B. A empresa familiar. 4a ed. São Paulo: Pioneira, 1993.

LONGENECKER, J, G; MOORE, C.W; PETTY, J.W. Administração de pequenas empresas. Trad. Maria Lúcia G. L. Rosa e Sidney Stancatti. São Paulo: Makron, 1997.

MDA- Ministério do Desenvolvimento Agrário. Disponível em: http://www. mda.gov.br/sitemda/noticias/cr\%C3\%A9dito-para-agricultura-familiarpossibilita-perman\%C3\%AAncia-de-jovem-no-campo Acesso em: 04 out. 2015 .

MINAS GERAIS, SECRETARIA DE AGRICUlTURA. Programa Sistema de Realidade Municipal. Emater/MG, 2004.
SPANEVELLO, R.M. 2008. A Situação das Filhas na Transmissão do Patrimônio da Agricultura Familiar. Proceedings Fazendo Gênero 8, Florianopolis, 25-28 August, 1-7.

WOORTMANN, E. Herdeiros, parentes e compadres: colonos do Sul e sitiantes no Nordeste. São Paulo: Hucitec; Brasília: Editora da UNB, 1995. 